\section{Pronouns, Positioning, and Persuasion in Top Nonprofits' Donor Appeals}

International Journal of Business Communication

(C) The Author(s) 2021

Article reuse guidelines: sagepub.com/journals-permissions DOI: 10.1 I77/232948842। I062174

journals.sagepub.com/home/job

(SAGE

\author{
Paula Lentz' (D), Kristen Getchell², James Dubinsky³, \\ and Mary Katherine Kerr ${ }^{4}$
}

\begin{abstract}
Despite increased giving in 2019, competition for donations among nonprofits remains high, especially when a charitable organization's niche overlaps with that of others'. Consequently, nonprofit charitable organizations must tell stories that persuade donors to support their mission and contribute. This study uses positioning theory to examine how websites of the charitable organizations that appeared in Forbes Magazine's 2019 top 100 charities use storytelling to facilitate their ethos such that they gain support and thus increase their donor base. The results revealed that nonprofits use positioning to establish two types of partnerships: invited and assumed. Furthermore, the coding revealed three primary types of positioning within these partnerships: savior-follower, business partners, and teacher-student. These positions organize and set the parameters for each organization's story and will not only influence and potentially dictate the speech acts that follow, but also the responsibilities and rights of all those involved.
\end{abstract}

\title{
Keywords
}

nonprofits, positioning theory, donor appeals, storytelling, persuasion

\footnotetext{
'University of Wisconsin-Eau Claire, USA

${ }^{2}$ Babson College, USA

${ }^{3}$ Virginia Tech, Blacksburg, USA

${ }^{4}$ UW Consortium MBA Program, Eau Claire, WI, USA

Corresponding Author:

Paula Lentz, College of Business, Department of Business Communication, University of Wisconsin-Eau Claire, 105 Garfield Avenue, P.O. Box 4004, Eau Claire, WI 54702-4004, USA.

Email: ginderpj@uwec.edu
} 
In 2019, Americans gave \$449.64 billion to charities, up 5.1\% from giving in 2018. Of that amount, $69 \%$ was given by individuals, $17 \%$ by foundations, $10 \%$ by bequest, and $5 \%$ by corporations (up $13.4 \%$ from 2018). As in 2018, the categories that received most of these funds in 2019 were religion (29\%), education (14\%), human services (12\%), grant-making foundations $(12 \%)$, and health $(9 \%)$ (National Philanthropic Trust, 2019).

Much of this largesse went to the more than 1.54 million nonprofit organizations registered with the US Internal Revenue Service, of which $75 \%$ are charitable organizations (Urban Institute, 2020). Of these charitable organizations, about half of them receive $\$ 50,000$ or less each year in donations (Better Business Bureau, 2018).

Despite increased giving in 2019, competition for donations among nonprofits remains high, especially when a charitable organization's niche overlaps with that of others'. Paarlberg and Hwang (2017) put it simply, the greater the overlap, the greater the competition for resources and donors. Consequently, nonprofit charitable organizations must tell stories that persuade donors to support their mission and contribute, and nonprofits are relying increasingly on having an online presence (Shier \& Handy, 2012) as a platform for their stories. While some research has examined the impact nonprofits' rhetorical strategies on social media platforms such as Twitter and Facebook (e.g., Auger, 2014; Cruz et al., 2017; Pang \& Law, 2017; Smitko, 2012), the research on successful rhetorical strategies nonprofits use on their websites as a means of telling their stories appears lacking.

Part of what makes a nonprofit organization's message successful is the compelling nature of its story and its ability to connect with funders and their missions. Some organizations tell their stories well - so well that they are wildly successful both in cultivating a large donor base and subsequently receiving many contributions or number of significant contributions. Forbes annually compiles a list of the top 100 most successful nonprofits in terms of fundraising, which receive a combined $\$ 51.1$ billion annually, or $12 \%$ of all charitable gifts (Barrett, n.d.). These nonprofits represent a range of categories, including education, culture, the environment, medicine, and veterans' affairs.

The purpose of this study is to understand how websites of the charitable organizations that appeared in Forbes Magazine's 2019 top 100 charities use storytelling to facilitate their ethos such that they gain support and thus increase their donor base. This research employs positioning theory to (A) examine how nonprofits use pronouns as a rhetorical strategy to persuade donors to provide financial support and (B) to assess how these strategies position top charities as reputable, capable, appealing, and worthy of support. While previous research on nonprofit communication addresses nonprofits' use of logos, ethos, and pathos, less research illustrates how nonprofits build and manage donor relationships via the positioning of the nonprofit to the donor, essentially to manage as Harré (2012) says, "disputable rights, obligations, and duties" of their and their donors' positions (p. 193). This research contributes to the body of literature on effective communication practices of successful nonprofits by using positioning theory (Davies \& Harré, 1990; Harré \& Langenhove, 1991; Van Langenhove \& Harre, 1999), as a framework for understanding how nonprofits use language to 
assign roles or assume roles for themselves and others in the stories they tell about themselves, particularly through the use of pronouns. Given its origin in marketing (Davies \& Harré, 1990), where companies find their niche or position among their competitors, it makes sense to use positioning theory as a lens for examining how nonprofits locate their product - their cause - among the vast pool of other nonprofits competing for the same thing: donor support.

While this study does not establish a causal relationship between nonprofits' positioning strategy and successful donor communication, we argue that storytelling as donor communication is essential in cultivating the donor base that has led to these organizations' successful fundraising. The results may provide other nonprofits with suggestions or models for honing their donor appeals, targeting their donor communication more intentionally, and growing their donor bases. In other words, these organizations are clearly good at what they do in cultivating a donor base; and while multiple factors likely contribute to this success, persuasive communication, too, as the literature establishes, is one of those critical factors.

\section{Literature Review}

Storytelling is central to a nonprofit's work. Mitchell and Clark (2021) establish a model that demonstrates a nonprofit organization's ability to tell its story and establish its purpose as either distinct from or typical of similar nonprofits is moderated by the organization's ability to tell a story that elicits an affective, behavioral response from the audience and conveyed brand impact (e.g., saliency, relevance, distinctiveness, credibility, and engagement); organizations that cannot establish brand impact with their stories are less successful (p. 154). Merchant et al. (2010) found that a factor in the success of a nonprofit's story lies in its ability to lead the reader through a gamut of emotions, which might range from anger or distress over people who are served by the nonprofit (e.g., hungry children) to joy over the organization's ability to help people in need. This "emotional pay-off" (p. 756) motivates people to donate, particularly when organizations share information with donors about how their donations helped the organization effect change.

Likewise, Choy (2017) cites the 2016 Burk Donor survey in which 44\% of 150,000 donors said they "could afford to give more if they heard the right things from nonprofits" (p. 188). According to Choy, getting donors to believe in the organization's mission is not enough to engage an audience, nor is it enough to rely on statistical data. Instead, a compelling story must resonate with the audience personally; the audience must see how their efforts benefit the cause or people they are helping and the impact their contributions make. In other words, these stories are persuasive and thus inherently rhetorical. The story is, as Gill and Wells (2014) found, a legitimating factor for a nonprofit in that it makes visible "the extent to which behavior reflects communication, or does the nonprofit do what it says it will do" (p. 27). In other words, delivering on its promises assists nonprofits to establish their ethos. Gill and Wells (2014), for example, use Mothers without Borders to illustrate how one nonprofit rhetorically constructs its identity on an ethos of shared values with its audience; in doing so, the 
organization builds symbolic capital (an ethos) and makes it more attractive to potential donors.

In addition, an organization's platform impacts the telling of its story. Auger (2014) found that "a person like me ethos strategy" was the most frequently used persuasive strategy in nonprofits' social media messages, followed by pathos (motivation) and then logos (facts). Pathos, however, was the most favored strategy by top organizations and the strategy most frequently found in tweets that appealed to the audience's sense of community in working toward goal attainment. Smitko (2012) and Pang and Law (2017) analyzed the Twitter feeds of two nonprofits and one for-profit organization. Both studies pointed to ethos as the dominant persuasive strategy.

Others, however, have found that the effectiveness of rhetorical strategies depends on the framing of the message. Das et al.'s (2008) research on nonprofits found that in positively framed messages (e.g., 10,000 people will live if people support the cause), anecdotal evidence was most effective; however, in negatively framed messages (e.g., 10,000 people will die if people don't support the cause), statistical evidence (i.e., logos) was most persuasive because messaging that promoted the likelihood of attaining the organization's goal motivated people to give.

On the other hand, for many organizations, pathos appears to be an effective, though risky, strategy. Masnovi (2013) found that respondents were most affected by pathos in advertisements asking for donations to the Hats Off for Cancer charity. However, Merchant et al. (2010) examined the impact of emotions (pathos) in donor motivation; they learned that donors might feel negative emotions when presented with the problem that a charitable organization is addressing, but donors may be moved to feeling positive emotions when they believe they are part of solving a problem. Thus, feedback from a charity to its donors regarding positive outcomes is a way to keep donors engaged. McKeever (2013), though, suggests that emotional appeals may not be an effective driving force in motivating donor engagement. In her study of appeals for participation in Relay for Life, she found that while prospective donors may feel an emotional connection to a charity's issue (in this case cancer), practical considerations such as time and money were greater forces that impacted their involvement. In fact, some research (Hung \& Wyer, 2009) reveals that asking donors to take a beneficiary's perspective is ineffective because the two experiences are not congruent. Therefore, the donors do not have sufficient sympathy or empathy to be compelled to give.

In summary, our literature review on effective rhetorical strategies indicates that no one strategy is most effective. Given the variety of nonprofits, the causes they support, and the donors they target, it is reasonable to conclude that their stories and arguments to achieve their communication and organizational goals will vary depending on many factors. Nonprofits construct their stories by learning to adapt their uses of logos, ethos, and pathos as they more fully understand the relationship between themselves and their audience. This balancing is socio-spatial analysis at play, which understands an entity (the nonprofit) in relation to other entities (potential and actual donors) and the repertoire of persuasive strategies available for managing the relationship. In the case of our study, we understand the relationship 
between nonprofits as an entity and their donors as an entity by relying on positioning theory as a lens.

\section{Positioning Theory}

Positioning theory is a framework for understanding how people or organizations use language to assign positions to themselves and to those around them and, in doing so, also assign rights and duties that come with these positions as people "are located in conversations as observably and subjectively coherent participants in jointly produced story lines" (Davies \& Harré, 1990, p. 48). Positioning within these conversations (which include the conversation's storyline and the speech acts within it) comes with "direct moral implications, such as some person or group being located as 'trusted' or 'distrusted,' 'with us' or 'against us,' 'to be saved' or 'to be wiped out'” (Moghaddam \& Harré, 2010, p. 2). Positioning itself, then, is made possible via the interplay of positions, the storylines, and speech acts.

Examined through the lens of positioning, any discourse can be analyzed to uncover an individual's or organization's motives and persuasive strategies. While we cannot know the rhetor's intent, when applying the lens of positioning theory, we can view speech acts not as measures of intent but as consequences of positioning itself and thus understand more fully the intent mirrored in these consequences. We explore this notion of intent and positioning theory below as we explain the three parts of the positioning triad below: positions, story lines, and speech acts.

\section{Positions}

While a position is related to the concept of a role, a role apart from its position implies a static space; Davies and Harré (1990) argue that a role, reframed as a position, carries with it the possibility for change, depending on the conversation at hand. People can assign positions to themselves (reflexive positioning) or assign positions to others or have positions assigned to them (interactive positioning) (Davies \& Harré, 1990). These positions are relative, changing, and contestable and come with their own expectations and responsibilities.

"Positions are identified in part by extracting the autobiographical aspects of a conversation in which it becomes possible to find out how each conversant conceives of themselves and of the other participants by seeing what position they take up and in what story, and how they are then positioned" (Davies \& Harré, 1990, p. 48). Likewise, these types of positions are ordered according to the act required by the positioning: First-order positioning refers to the initial act of positioning oneself or someone else. Second-order positioning happens when someone contests, questions, or negotiates the first-order positioning within the current conversation. Third-order positioning occurs in new conversations once people have been repositioned.

In addition to positioning acts, people can be positioned or position themselves according to the role the position requires them to play. For example, moral positioning occurs when someone is positioned into a "recognizable social role" such as that 
of a doctor, while strategic positioning refers to the "rights and duties that are to the advantage of the person who performs the positioning acts" (Moghaddam et al., 2008, p. 294) such as in the case of a doctor, who, as a result of their of their knowledge, education, and capability to heal others assumes the moral position of a group of people who are generally trusted (or whom people have to trust) because of their power to heal or save lives - a power the average person does not have. Furthermore, these types of positioning can include those that position people as part of a group or outside that group (mutual positioning) or even harmful ("malignant" or "malevolent" positioning). One note here, though, is that Davies and Harré (1990), Van Langenhove and Harre (1999), and Harré (2012) are careful to distinguish a role from a position, saying positioning theory "helps focus attention on dynamic aspects of encounters in contrast to the way in which the use of 'role' serves to highlight static, formal and ritualistic aspects." Positions, however, do not operate independent of the conversations they are in, nor are people positioned independently of the conversation and others within that conversation.

\section{Storylines}

According to Davies and Harré (1990), a conversation is "the starting point we proceed by assuming that every conversation is a discussion of a topic and the telling of, whether explicitly or implicitly, one or more personal stories. . ." (p. 48). People organize their stories in two ways: by logic and by storyline. And within these ways of organizing are the positions, the speech acts comprising the story, and the storyline itself. The storyline, as Harré and Van Langenhove (2010) note, is never "freely constructed" (p. 111). Rather, the storyline reflects the "repertoire of competent members" (p. 111) within the discourse community and the community's culture. The telling of this story is dynamic, and participants in the storyline are continually able to assume or negotiate their positions or be positioned by others; so, too, are the moral roles and obligations assigned or assumed in the telling of the story.

\section{Speech Acts}

Davies and Harré (1990) emphasize that one distinguishing feature of positioning theory is that it frames the speech act as a consequence of the social action or interaction within a conversation. Understood in the context of a nonprofit's donor appeals, then, positioning theory does not concern itself with the rhetor's intent so much as it concerns itself with the ways in which the storyline and its embedded conversation and social context impact the ways in which "a conversation unfolds through joint action of all the participants as they make (or attempt to make) their own and each other's actions socially determinate" (p. 45). In other words, because of the socially constructed nature of conversations and the culturally influenced storylines within them, the rhetor's intent of their words is not so much of consequence as is the meaning it takes on as a result of the consequences incurred as all participants engage in 
exchanges within that conversational context. Positions assigned, assumed, or negotiated within these conversations will impact the consequences of a speech act, as will any community-established moral roles assigned or assumed by various positions.

\section{Pronouns and Positioning as a Means of Persuasion}

While positioning theory allows for many ways in which positions are assigned, assumed, and negotiated, for this paper, we are using the lens of positioning theory to examine how pronoun use, in particular, is one way nonprofits position themselves and their donors in their stories such that donors feel compelled to support the organization; the fact that the nonprofits in this study are the top ranking US nonprofits based on donor contributions is evidence that these organizations tell their stories to good effect, and, as we will discuss later in this paper, pronouns are central to the telling of these stories.

The use of pronouns as a means of understanding positioning is well documented. Pronouns, by definition, are those words that represent or refer to proper or common nouns. First person pronouns (e.g., I, me, we, us, our, ours) refer to the speaker or writer of a message; second person (e.g., you, your), to the audience; and third person (e.g., he, him, she, her) to people external to the message (Íñigo-Mora, 2004). Harré and Gillett (1994) and Mühlhäusler and Harré (1990), illustrate how first-person pronouns indicate that the rhetor perceives a close relationship between themselves and the audience, relative to the social context in which the communication occurs. Furthermore, pronouns are not neutral; they both reflect and are reflected by the social context in which they are used. Pennebaker (2011) notes that pronouns are small words that have a significant impact in how we show others who we are and what we do.

\section{Function of Pronouns: Relationships}

Pronouns not only limited focus on one's identity; they also serve as a means of establishing the relationship between the rhetor and the audience. One particularly impactful use of pronouns is for community-building. First-person pronouns, for example, create the least distance from the writer or speaker, while third-person pronouns create the most. "We" and other first-person pronouns are frequently used in organizations' communication with constituents, customers, and stakeholders. Their impact comes from their community-building function through the judicious use of the "external we" versus the "internal we."

The "exclusive we" refers to the rhetor and the rhetor's group or organization but excludes the audience and thus establishes a power hierarchy in which the organization positions itself as the authority (Fahnestock, 2011). For instance, people writing sales messages to potential customers on behalf of their companies will use "we" or "us" rather than "I" to establish the relationship between the rhetor and the company; in doing so, the audience is excluded from that community: We (the rhetor and company) can offer you (the potential customer) $30 \%$ off your first order. If you are not 
satisfied with your purchase, you can return it within 30 days, and we (the company, not the rhetor) will refund your money.

On the other hand, "we" can also be inclusive of both the rhetor and the audiencethe "I" and the "you." The inclusive "we," also called the "royal we" or the "majestic we," builds a relationship with the audience by inviting the audience to belong to the rhetor's community, and it "diminishes the responsibilities of the speaker, since he or she is portrayed as collaborating with the hearer" (Mühlhäusler \& Harré, 1990, p. 175). An example of the inclusive "we" would include a charitable organization saying to its donors "With your support, we can end childhood cancer." The we in this case refers to the collaboration between the writer and the reader.

\section{Pronoun Use by Nonprofits: Purpose and Use}

Researchers in corpus linguistics have examined the discursive practices of pronoun use among nonprofits and have found pronouns assume a distinct function in nonprofits' communication. Crismore (2004), in examining the linguistic and rhetorical uses of pronouns in two distinct nonprofits' fundraising letters (education and healthcare), discovered that the eight most frequently used pronouns in both fields, in rank order from most to least, were you, your, our, we, I, us, my, and we. She concludes that in both fields, organizations recognized the rhetorical power of pronouns for establishing credibility and style (first-person singular), reader engagement (first-person plural and second-person pronouns), and nonprofit-donor solidarity (first-person singular firstperson plural, and second-person pronouns).

Likewise, Connor and Gladkov (2004) applied a corpus linguistics approach to analyze rhetorical appeals in 245 nonprofits' direct mail letters; they then compared the frequency of words in those letters with the frequency of those words in the Bank of General English and found that pronouns are used differently and with more frequency than they are in the Bank of General English. "You" is the most frequent pronoun, for instance, in nonprofit direct mail letters, while $I$ is the most frequent in the Bank's word list. "We" is the 13th most frequently used word in fundraising texts; it appears 33rd in the Bank. Like Crismore (2004) they conclude that the rhetorical purpose of nonprofits drives the use of pronouns to promote inclusivity, convey a personal relationship with the audience, and create a sense of shared purpose.

\section{Use of Pronouns in Marketing}

Nonprofits are marketers of their organizations, and as such, it seems logical that marketing literature would also inform our understanding of the impact of pronoun use on the audience, and pronouns have, in fact, received frequent attention in marketing research. Packard et al. (2018) found that the standard advice to avoid the "I" is not as helpful as using the pronoun judiciously. When customer service agents used "I" rather than "we" (the company), customers felt that the agent was more caring or invested in the customer's concern. Kachersky and Palermo (2013) researched the use of $I$ and $m y$ in brand names (e.g., iPhone, MySpace) and found that brand names including a verb 
received positive customer responses when $I$ was used (e.g., iRead), and brand names using a noun received positive customer reactions when nouns were part of the name (e.g., myReader).

Sela et al. (2012) conducted four experiments to examine the effects of pronouns on feelings of consumers' closeness and relationships to a brand and found that consumers' connectedness to a brand was positively influenced by the use of the inclusive "we" when the consumers' expected level of closeness to the brand was consistent with the closeness implied by the pronoun. They concluded that

Language is a medium that specifically characterizes interpersonal interactions, as opposed to pricing, which characterizes business entities such as brands. Therefore, our findings uniquely illustrate and validate the notion that people sometimes truly think of brands as if they were other people, responding to differences even in language use (p. 656).

Cruz et al. (2017) additionally found in their analysis of Facebook posts that second-person pronouns enhance consumer involvement and brand attitude in their ability to personalize messages, which then led to increased engagement as evidenced by likes, shares, and comments. One interesting facet of their study, however, is that they add to the discussion of persuasiveness via the discussion of collectivistic values. That is, for people who had low or moderate levels of collectivistic values, the use of the second-person you resulted in higher levels of engagement and improved brand attitude. Those with high collectivistic values were not affected by the use of you.

Given the utility of positioning theory and prior research on the strategic use of pronouns for persuasion, this paper applies positioning theory to the analysis of the 100 nonprofits listed in the Forbes list of the top 100 US nonprofits by donor contributions. In doing so, we answer the following questions:

1. Social Positioning: How does the organization's use of pronouns reveal types of social positioning in the nonprofits' messaging to their audiences relative to the conversational space they occupy (e.g., education, medicine, veterans' affairs)?

2. Moral Positioning: How do nonprofit organizations use pronouns to establish moral order and moral responsibilities for themselves and their audiences?

\section{Method}

The process of answering our research questions required coding and interpretive work on many levels. We started by examining the websites for each organization in the Forbes list and found that the websites for nonprofit organizations ranged in density of pages and business. We had two goals when identifying which pages to analyze: First, we wanted to make sure we could identify pages that would be comparable across sites. Second, we wanted to identify pages that clearly had the donor as the 
audience and where a clear appeal to donate was made. To that end, we chose the home page, donor landing page, and donation page as the artifacts for our pilot study. As we mention in the introduction to this piece, the Forbes list has been used as a research sample in business studies that use methods examining the magazine's content itself. Getchell and Beitelspacher (2020) use the Forbes list of Top CMOs to identify gendered language in the description of male and female chief marketing executives. Other researchers, including the researchers of this study, have used the list to outline a sample for analysis. Chan et al. (2017) and several others (Klass et al., 2006) have studied the wealth distribution of the Forbes list of the richest Americans in the US. Looking at the statistical regularity of wealth distribution on the list, these researchers are making inferences about wealth distribution at all levels.

To aid in research design, test our methodology, and get a sense of the appropriateness of our sample choices, we analyzed a small sample of organizations in three of the categories Forbes assigns to the charities on its list: environment/animals (10 pages, 5 charities), medical (21 pages, 10 charities), and veteran's needs/domestic needs (19 pages, 5 charities). The categories were chosen based on our personal interest in the nonprofits. We analyzed both frequency of pronoun use as well as the contextual use and positioning created with use.

We coded the data using NVivo software to analyze pronoun frequency in all of the landing and donor pages in these three categories: first-person plural inclusive, firstperson plural exclusive, first-person singular, second person, third person. A graduate assistant coded all three sections; each researcher then checked the graduate student's code for one of the Forbes categories. During this process, we found that coding for the first-person plural inclusive and exclusive required a decision on the part of the coder beyond mere identification. The coder needed to use the rest of the sentence and context to assign a code.

We analyzed the pronouns for $20 \%$ of the nonprofits in each of the three categories for two types of positioning based on previous research: social and moral. Social positioning refers to the relationships between the nonprofits and donors-power, knowledge, trust, ethos. Moral positioning refers to authority and moral responsibility.

Our initial findings, presented at the 2020 Association for Business Communication conference, showed that second-person pronouns were the most frequently used pronoun across all categories. First person exclusive pronouns were the second more common. We also found that social positioning is demonstrated through subtle prevalence of each type of pronoun. For example, second-person pronouns position the reader as part of the organization's story. We also found that first-person pronouns seem to establish the moral positioning: the organization is worthy of the donor's trust.

Having tested our coding process and reviewed our interpretive process of the positioning in the nonprofits,' we expanded the sample size and refined the coding. The resulting focus is on the relationship between writer and audience and involves three levels of coding, with each level being more granular than the previous level.

We began by expanding our sample from 20 companies to the entire list of 100 nonprofit organizations. By expanding our sample, we coded the number and type of pronouns on the home and donor pages for all 100 nonprofits in all 11 of Forbes's 
categories: cultural, domestic needs, education, environment-animals, health, international needs, medical, public affairs, public broadcasting, religious, and youth. Counting the number and type of pronouns on all 100 nonprofits' pages ensured that, when we eventually targeted our interpretation of the use of the pronouns as a positioning strategy to the to top 25 nonprofits, we had reached a sample saturation point (Saunders et al., 2018). Thus, we considered our sample size in the following ways:

We chose the Forbes' list as our methodological research site for its ranking and its precedent in research (e.g., Chan et al., 2017; Klass et al., 2006). At this first round of coding, we coded only for the presence and frequency of first-person pronouns (both inclusive of the reader and exclusive), second-person pronouns (which included separate coding for the presence of the pronoun and the imperative mode), and third-person pronouns. Because of the binary nature of the coding and inherent objectivity (i.e., words are either pronouns or they are not, and the pronouns are not subjectively categorized as first-, second-, and third person) and because NVivo could readily count the pronoun frequency, we had no reason to stop coding short of the entire list.

We checked inter-coder reliability (ICR) in two ways: (1) by reviewing $20 \%$ of the sample for general accuracy and (2) by reviewing first-person pronouns in their entirety to determine accuracy of inclusive and exclusive varieties. We did not, however, calculate an inter-coder reliability value, as the coding of a pronoun as first-, second-, or third-person was not an interpretive act; the pronouns fit only into one identifiable classification, so we reviewed one another's codes for their accuracy. Per the arguments and guidelines regarding ICR outlined by O'Connor and Joffe (2020), calculating an ICR did not appear to benefit this study. The results of this coding are presented in Table 1. Counting and categorizing the pronouns provided a sense of whether and how much nonprofits were using pronouns. However, positioning theory is not concerned with the quantity of pronouns used, only with where and how they are used; the counting served only as a guide to us for where to locate pronouns at individual nonprofits' webpages. As the purpose of this paper was to determine how these pronouns are used, the quantity of the pronouns was not a consideration after this point.

We then identified the top $20 \%$ of nonprofits within each of the Forbes's categories that had the highest frequency of pronoun counts for further review, which led us to analyze 25 organizations ( $25 \%$ of the sample) for their use of pronouns to establish positions. Specifically, we identified how the pronoun use on the home page positioned the organization in relationship to others by examining assumptions, positions, rights and duties, and storylines evident in the pronoun use and positioning.

Finally, based on this coding, we were able to code further to identify nine primary types of positioning that fall into three general categories in which the organizations positioned themselves and/or the donors in (1) a spiritual or religious context: evangelist/ missionary, religious or spiritual guide; and savior; (2) a corporate or business context: partners, participants in a business transaction, visionaries, or administrators/logistics experts; and (3) a social activism or humanitarian context: teachers, advocates, and protectors and defenders. It is important to note that the category in which the organization 


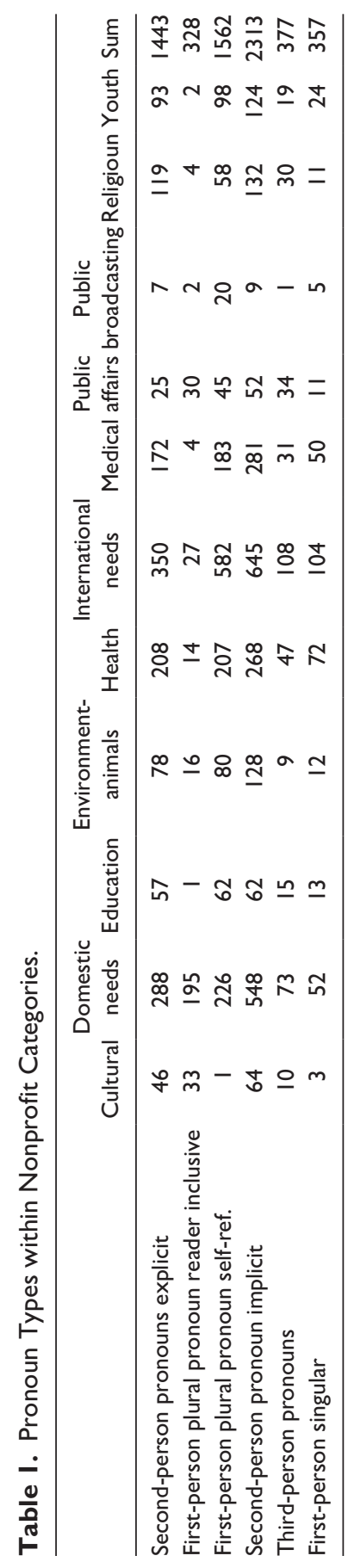


is placed regarding positioning type is not related to the type of organization. For example, many organizations in our 25-item sample are not religious organizations (e.g., Susan G. Komen Foundation), but because they position themselves as a savior (a term with strong religious connotations), they are coded in the spiritual or religious context. The analysis that follows outlines the positions that are assumed and assigned, along with the rights and responsibilities conferred by these positions.

\section{Analysis and Discussion}

In this section, we answer our initial research questions: (1) Social Positioning: How does the organization's use of pronouns reveal types of social positioning in the nonprofits' messaging to their audiences relative to the conversational space they occupy (e.g., education, medicine, veterans affairs)? (2) Moral Positioning: How do nonprofit organizations use pronouns to establish moral order and moral responsibilities for themselves and their audiences? Our focus is this first-order positioning, as we cannot know whether audiences accept or reject this positioning, nor would they seem in a position to negotiate - though perhaps it could be assumed that donors accept or reject these positions when they opt to donate or not donate.

To present the analysis and discussion of these nonprofits' use of positioning across the nine types within three categories, we have chosen exemplars from each category as the focus of the presentation. Briefly, however, the 25 nonprofits' sites that were coded in the third round are classified as presented in Table 2. The Forbes category for each site is in parentheses after the nonprofits' name. While Table 2 summarizes the categories of positions, Table 3 presents the key findings by the 11 Forbes categories to show the distribution of positions across the types of categories that Forbes assigns to the 25 nonprofits that we analyzed.

\section{Partnerships Assumed and Invited}

Our analysis showed that all of these organizations described some type of partnership with their audience. These partnerships were generally described as a way to build positive change together. However, there were two patterns of pronoun use in this type of positioning and the difference in use established two types of partnership: assumed and invited. Please note that here and throughout the analysis and discussion, we have bolded the relevant pronouns to highlight their use.

The assumed partnership position tends to use first-person plural inclusive pronouns and second-person pronouns to establish a connection between the organization and the audience. However, the use of the first-person plural inclusive and secondperson pronouns assumes that the audience is part of that "we" already, that they are a partner in the mission. The Christian Broadcasting network and Operation Blessing home page provides an example of this type of assumed partner positioning:

Operation Blessing is a nonprofit, humanitarian organization dedicated to partnering with you to demonstrate God's love by alleviating human suffering in the U.S. and around the 


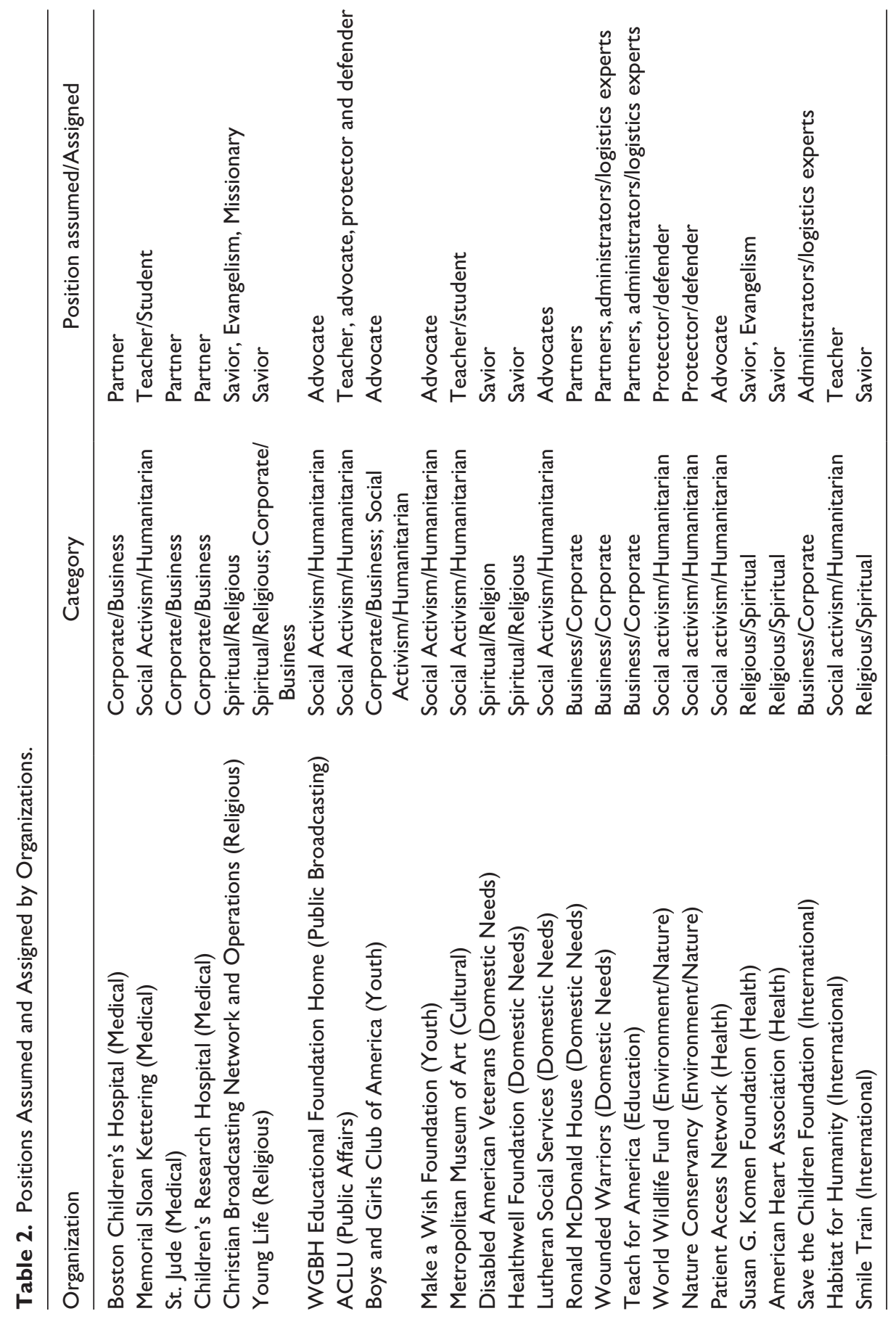




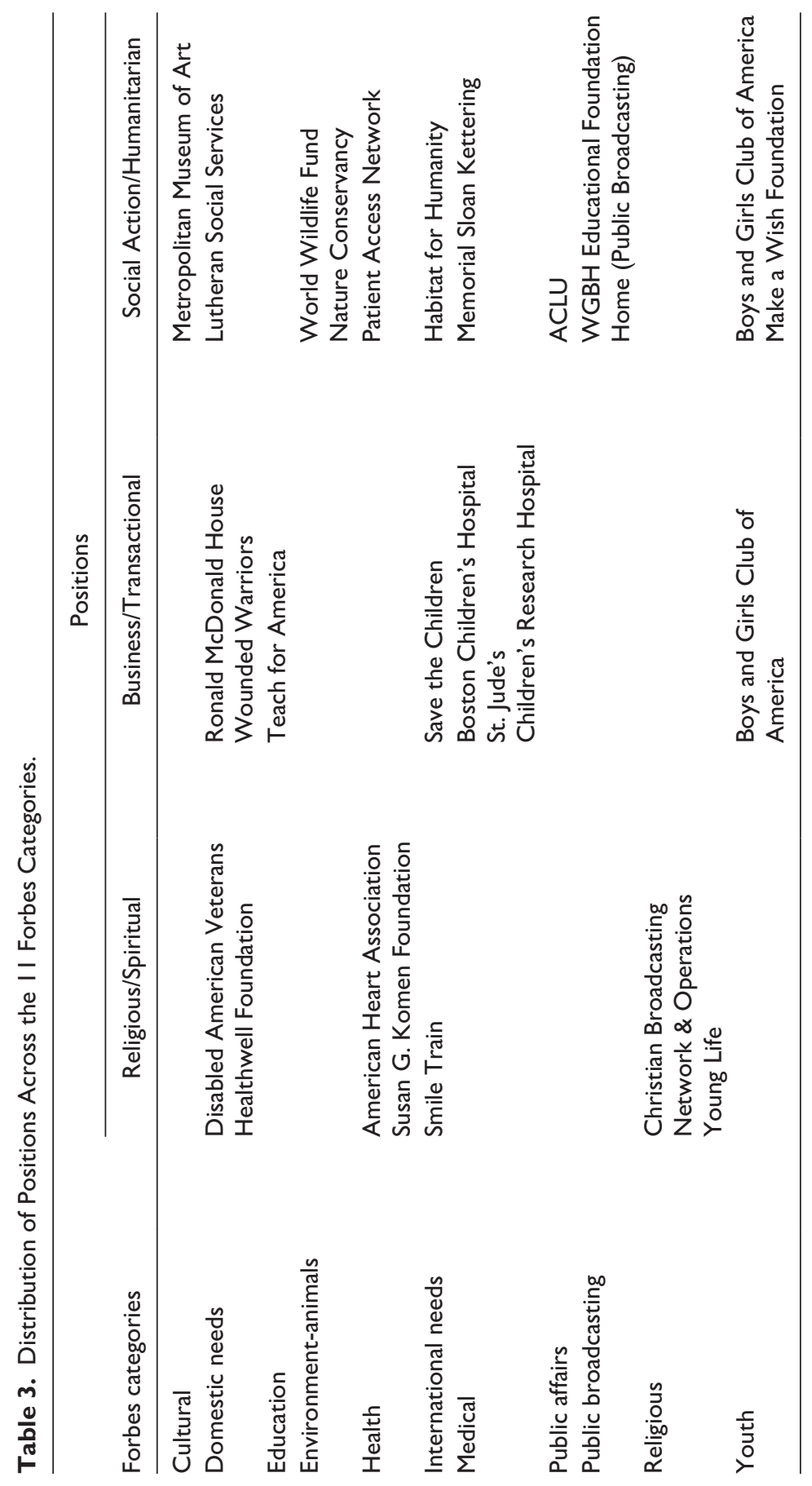


world. For more than 40 years, your love has shown through OB as together we've provided hunger relief, medical care, clean water, and disaster relief to millions around the world.

Here the partnership is a central part of their mission. And the action is a joint action: "together we've provided hunger relief. .." with the "we" referring to both the nonprofit and the audience. The centrality of the partnership in this mission shows that the organization values the partnership and views the reader as part of the work of the organization.

Conversely, in an invited partnership, the organization positions itself differently. Instead of the first-person pronoun inclusive, the nonprofit uses more first-person plural exclusive and second person, and the effect is an established separation between the nonprofit and their audience. And there is a marked power difference evident as well, with the organization assuming the role of the inviter and the audience the invitee.

St. Jude Research Hospital is an exemplar of this type; it takes the position of inviter on its homepage. Much of the content is about what the hospital does (exclusive of the audience). Headings include exclusive pronoun use that describes the work of the organization: "Explore our Research," "Learn more about Us," "Treating the toughest cases." Even their main heading, "Finding cures. Saving children." seems to have an implied first person plural exclusive: We are finding cures. We are saving children.

However, there is a shift in pronoun use when St. Jude Research Hospital invites its audience to partner with them on this work. Above the "Donate Now" button are the words "Let's cure childhood cancer. Together." This invited partnership (and inclusive contraction of "us") demonstrates an invitation of sorts. If the audience would like to join St. Jude's in their work, they can click the button to donate and become a partner. However, different from the assumed partnership, this partnership, as designed by the organization, has a specific requirement: donation. The organization has set the terms of the partnership, and the role of the audience is narrowly defined. They are not experts. They are responsible for financial support.

The type of partnership differs depending on the lens through which the organization positions themselves in relationship to others. Some organizations assume the power to invite the reader, set the terms of partnership, and as a result establish whether the partnership is an equal one. Because they assume the power to invite the reader, they are positioning the reader and themselves in ways that we felt fell into three categories of metaphor with characteristics of this relationship. In the first category, the charity is positioning itself as savior with the audience as their followers, in the second the charity is positioning itself as enterprise managers with the audience as business collaborators or shareholders, and in the third the organization is positioning itself as social activist or humanitarian inviting the audience to join the nonprofit as advocates, protectors, and defenders.

\section{Religious/Spiritual Positions}

The types of positions assigned in this category are those in which the organizations position themselves as unique among all other organizations as the one that can "save" 
the population whom it serves. Whether the organization itself is affiliated with a religious institution is largely irrelevant. In fact, some religious organizations did not position themselves in the savior role at all (e.g., World Youth). When the social positioning of the organization is that of a savior, the position of the donor then becomes that of the follower.

The Disabled American Veterans's (DAV) site serves as the exemplar for the nonprofits in the Forbes list that position themselves and the audience in the savior-follower role. While most of the DAV's references to itself are the third-person "DAV," when the DAV positions itself and its audience, it does so primarily with first-person exclusive pronouns. The DAV employs a fair number of imperatives to command the audience to "Donate," "Learn more," and "Support Veterans," but the clearly established role is that of the DAV as the one responsible for helping or "saving" veterans, while the donors make the help possible. For example, one of the captions in a photo in the slider at the top of the page reads "Help us make a real difference in a veteran's life." The first-person pronoun use is consistent with the third-person references in the captions for the rest of the photos: DAV helps veterans get the benefits they deserve," "DAV helps veterans on their most important tour; the tour of their lives," and "DAV is continuing our mission in the face of COVID-19." Likewise, in providing data to support its success, the website tells readers "With your donations, DAV helped over a million veterans and their families in 2020. Learn more about our impact." Yet, by the time the audience gets to the end of the page, the use of the inclusive first person becomes obvious with statements such as "Help make sure that, after defending our freedom, our heroes and their loved ones get the care they earned." At the bottom of the homepage, veterans are invited to join the DAV, while others are encouraged to support the DAV by donating, becoming an advocate, or "Volunteer[ing] and stand[ing] with our nation's disabled veterans."

The pronoun use on the homepage demonstrates an order to the social positioning. The use of the exclusive first-person announces the DAV (Pennebaker, 2011) as a group well-positioned to save disabled American veterans from many of the challenges they face. In using the first-person, the DAV also establishes a close relationship between the organization and the audience (Mühlhäusler \& Harré, 1990). The shift to the inclusive first person strengthens that relationship further by inviting people to the DAV community and, as Mühlhäusler and Harré (1990) say, makes the audience a "collaborator" in the effort (p. 175). The audience, with their commitments to volunteer, donate, or advocate, remain positioned in a subordinate role to the DAV, but they gain some status as collaborators in the effort as they become followers of the DAV and its saving efforts.

The resulting moral position, then, becomes one in which the nonprofit is the keeper of the expertise that allows them to be trusted to make the right decisions regarding how they use the donors' contributions to "save" veterans by removing barriers they may face to healthcare or other benefits and resources (Moghaddam \& Harré, 2010). Such positions are advantageous to the nonprofits (Davies \& Harré, 1990) because they give nonprofits an authority and ethos available to those who have the power to save. The rights and responsibilities (Davies \& Harré, 1990) that come with these 
moral positions are further evident on the DAV's donor page and related "Help the DAV page" in which the use of the inclusive first-person "our veterans" is less prevalent than the use of first and second-person pronouns to establish the positions of savior-follower. For example, the donor page tells the reader that "Only with your support are we able to help more than 1 million veterans every year access the. . . benefits they have earned. . .Your gift gives ill and injured veterans the opportunity to live a life with respect and dignity." The relationship among the veterans is framed in terms of what they have "earned" or "deserve" as a result of their many sacrifices. The second-person pronouns reinforce that the audience is a fortunate "other" who did not or could not make such a sacrifice but who can show appreciation by joining with an organization that is able to help.

\section{Business/Transactional Positions}

The types of positions assigned in this category are ones in which the nonprofits position themselves in their story as business professionals whose interactions with donors are framed as business transactions in which donors are assumed to be partners or are invited to be a business partner. Specifically, nonprofits in this category are likely to assume roles as visionaries, logistics experts, entrepreneurs, or administrative gurus who enable donors to make the organization successful (and, of course, thus help the people whom the nonprofit serves). The audience is positioned as an investor or financier, and in some cases, the customer who can select between several products of donation.

Evident in this category from our analysis was that the organization positions itself as able to both see and solve problems of the future. Much like an early entrepreneurial startup, this positioning often creates distance between the organization and the audience, but also separates the organization from other organizations of its type. These organizations relied heavily on the first person plural exclusive to position themselves and established a forward-looking orientation toward their own work, with much of the action of the organization taking place in future.

Boston Children's Hospital's page illustrates the characteristics of this category. The first text the reader sees on the homepage is "From the frontlines of patient care to the forefront of discovery, our dedication to kids never stops." The use of the firstperson pronoun dominates the page as the organization establishes its ethos through such means as referencing its Number 1 ranking as "a testament to our fierce commitment to families, and the trust they place in us to deliver care when it matters most." The trust is augmented by the social positioning of the "our" and "us" as in a place of trust by the "they" third-person reference is clear. The hospital, with its science and medical expertise, provides care that saves children's lives; it offers specialized, exclusive expertise. The second-person use of pronouns on the home page invites the reader to help: "Your feedback helps us improve and provide the best care to all patients and families."

The role of the audience in the relationship is to provide financial support to the work of the organization, but there is no invitation for them to be a part of it, as is 
evident in the following where the organization asks the donor to contribute to help the organization achieve "our" (exclusive) goal: "Your gift to Boston Children's Hospital helps treat the whole child, supports families, funds lifesaving research and helps us pursue our goal: to give all children a healthy future."

Later on the home page, the organization continues to use the first-person plural exclusive to position themselves in relationship to their competitors as seen in this quote from their CEO Sandra Fenwick: "We are proud to serve a broad and diverse patient population that often comes to us for answers they can't find anywhere else." Here the organization positions itself in relationship to other organizations: The hospital solves the worst problems. It continues to separate itself from other organizations as the quote continues, "This top ranking is a credit and a tribute to our extraordinary and deeply committed clinicians, researchers and so many others who dedicate every day to improving and advancing the health and well-being of all children." Worth noting here is that there is no mention of the donor specifically in this recognition whether through second person or first person plural inclusive.

While the homepage establishes the hospital in the position of the visionary, the donor page establishes the donor in the transactionary role of investor. The site offers both a "Donate" option, which is an online form, and a "Ways to help" page in which the combination of first and second-person pronouns establish the audience as followers who can choose their "product" of donation: their time, their blood, their skills at organizing a running event, and even artwork.

\section{Social Action/Humanitarian Positions}

The nonprofits in this category are those where the organization positioned itself as teachers, social justice advocates, or protectors and defenders of animals or the environment. Their common purpose in extending or assuming partnerships with their audiences, however, appeared to be to educate their audience about the population or cause they serve, creating the impression that knowledge is power- that partners in this endeavor need to be educated about the cause and its importance in order to be motivated to serve.

The exemplar in this category is the World Wildlife Fund (WWF). Like other websites in this category, it is characterized predominantly by the use of secondperson pronouns, explicitly stated "you" and "your" but also the implied or imperative "you." First-person pronouns are present but not prevalent. Per Crismore (2004) and Cruz et al. (2017), this predominant use of second-person pronouns would suggest an attempt to engage the audience and encourage a positive attitude about the organization's brand. The trick to creating a positive attitude about the organization's brand appears connected to educating the audience about the organizations chief cause, which, in the case of the nonprofits in this category, is somewhat more of a niche than those nonprofits in the savior-follower or business categories. That is, St. Jude's hospital may have its chief cause providing care for sick children, but the breadth of people they serve and the types of illnesses they treat hit home, perhaps, more closely than that of a nonprofit working on water 
quality, wildlife preservation, or the opera that an audience may not be able to directly empathize with.

In any case, the use of second-person pronouns engages the audience through invitations to education via videos, podcasts, or reading material. The social positioning evident in the websites for the nonprofits in this category is one in which the organization is the teacher and the audience the student, both with the desire to be advocates for the population served by the charity.

The WWF, for example, invites potential donors to educational opportunities by paring video links with photos and text such as "One powerful thing you can do to help people and nature thrive? Vote," "[You]Watch the video and pledge to protect pangolins," and "[You]Give monthly to help protect elephants and other species." Not all of the videos contain headlines with the "you" pronoun, but they are sufficiently prevalent in the text that accompanies the videos in the montage as to suggest an invitation to the reader to engage.

Following the educational videos and the "you" focused invitations to learn is the transition to the "How you can help" section of the page. Here, first-person pronouns become prominent again as the organization continues in the social positioning of teacher-student. Assuming the reader has accepted the invitation to view the educational videos, WWF provides additional educational videos that are paired with text containing both first- and second-person pronouns: "[You]Join us for the first-ever WWF Species Step Challenge this October to celebrate wildlife and our planet," "[You]Take action today to help us save the most trafficked mammal in the world," and "[You]Help us reach our fall membership drive goal and protect nature." At this point, the videos still offer educational opportunities, but the introduction of the first-person pronouns (both inclusive and exclusive) suggests that the audience/student can now join the teacher/WWF as an advocate and saver of the planet. That relationship is cemented when the reader goes to the "Donate" page and is greeted with this text: "WWF's fall membership drive is ending soon! By September 30, we need to find 2,500 people to protect our planet. With you by our side, we will build a future where people live in harmony with nature. Please become a monthly member today." The first-person inclusive, first-person exclusive, and second-person pronouns establish the social positioning and parameters for this partnership. The moral positioning reflects a student-teacher relationship in which the teacher assumes the primary leadership role and position of power while the student's role is to learn and respond.

\section{Discussion}

The fact that these charities continually make the Forbes list suggests that they tell a story so powerful that donors, who have multitudes of charities to choose from, choose to support the charities on this list. So, what about these positions and subsequent stories make these organizations worthy of donation? Each of these positions appeal to donors differently through their positioning, suggesting a different type of action or response from the donor, each of them powerful in their own way. 
In the savior category the appeal is faith. A donor must trust that the organization can leverage its expertise or knowledge to solve the problems that they are unable to solve, and they must put their faith in the organization to deliver. After all, the audience is not the expert in the scenario and their rights are limited; their responsibility is to follow.

In the business category, donors are comforted by the transactional nature of business: they are making a good investment with their money and the organization is making good use of their time.

In the final category, the appeal is one of social responsibility. The organization in the final category is appealing to the donor to perform their advocacy duty.

Through their positioning, these organizations are shaping storylines. This is the starting point of a conversation and these positions organize and set the parameters for the story and will influence and potentially dictate the speech acts that follow, but also the responsibilities and rights. These positions can be negotiated in the future, but we can't know if and how they will be. While we can't know directly whether the audiences are accepting the positions that are assigned to them, we can assume that since they are willing to give their money - they are accepting the position that is assigned. We assume that if a donor does not accept this position, they will not donate. We can concur that there are many people who are willing to accept their positions as followers to a strong savior, investors in a business enterprise, or as advocates in a social cause.

\section{Limitations of this Study}

This study was designed to examine the positioning evident in the pronoun use of organizations in their donor messages. From this study, we are not able to make claims of intentional strategy. And while establishing intentionality is not required for understanding how positions impact a storyline, we do believe that there are questions about what goes on in an organization (in the minds of the copywriter, designer, marketer) when they are designing campaigns of this sort regarding how they can establish relationships with donors. In addition, the focus on pronouns means that we excluded elements of visual rhetoric that are essential to crafting a story, such as photos of starving children, disaster-affected areas, ill patients, or veterans in wheelchairs. Certainly, these elements were outside of the scope of this study, but future studies may want to take these features into account in tandem with the text. Extending the use of positioning theory to examining an organization's or individual's pronoun use in other types of communication (e.g., social media) would also be an interesting avenue of research.

\section{Conclusion}

This research has scholarly and practical implications. First, we see this research as part of a necessary conversation about the use of positioning theory to understand phenomena beyond implication for ethos (credibility) and pathos (credibility) to see the value for understanding more complex stories. These organizations have built 
credibility based on their size and amount of donations each year; however, we can understand organizations better when we move beyond just the organization and what it does and look at the relationship the organization creates with its donor and how this relationship allows them to continue to do their work.

We see this research having direct implications for practitioners who are working with nonprofit organizations to craft their stories. As mentioned in the discussion, based on the financial success of their campaigns, these organizations seem to have identified positions that are effective for their audiences. Therefore, nonprofits may want to consider using these positions. Nonprofits who want to tell their stories well, should consider this research knowing that these are positions that audiences seem to be willing to accept.

\section{Authors' Note}

This manuscript is original and is not under consideration or published elsewhere.

\section{Declaration of Conflicting Interests}

The author(s) declared no potential conflicts of interest with respect to the research, authorship, and/or publication of this article.

\section{Funding}

The author(s) received no financial support for the research, authorship, and/or publication of this article.

\section{ORCID iD}

Paula Lentz (D) https://orcid.org/0000-0002-5259-8249

\section{References}

Auger, G. A. (2014). Rhetorical framing: Examining the message structure of nonprofit organizations on Twitter. International Journal of Nonprofit and Voluntary Sector Marketing, 19, 239-249. https://doi.org/10.1002/nvsm.1499

Barrett, W. P. (n.d.). America's top charities 2019. Forbes. Retrieved August 8, 2020, from https://www.forbes.com/lists/top-charities/\#2219d7b5f501

Better Business Bureau. (2018, May 9). Wise Giving Wednesday: How many U.S. charities are there? https://www.give.org/news-updates/2018/05/09/wise-giving-wednesdayhow-many-u.s.-charities-are-there

Chan, S., Chu, J., \& Nadarajah, S. (2017). Is the wealth of the Forbes 400 lists really Pareto distributed? Economics Letters, 152(C), 9-14. https://doi.org/10.1016/j.econlet.2016.12.017

Choy, E. (2017). Let the story do the work: The art of storytelling for business success. AMACom.

Connor, U., \& Gladkov, K. (2004). Rhetorical appeals in fundraising direct mail letters. In U. Connor \& T. A. Upton (Eds.), Discourse in the professions (pp. 257-286). John Benjamins.

Crismore, A. (2004). Pronouns and metadiscourse as interpersonal rhetorical devices in fundraising letters: A corpus linguistic analysis. In U. Connor \& T. A. Upton (Eds.), Discourse in the professions (pp. 307-330). John Benjamins. 
Cruz, R. E., Leonhardt, J. M., \& Pezzuti, T. (2017). Second person pronouns enhance consumer involvement and brand attitude. Journal of Interactive Marketing, 39, 104-116. https://doi. org/10.1016/j.intmar.2017.05.001

Das, E., Kerkhof, P., \& Kuiper, J. (2008). Improving the effectiveness of fundraising messages: The impact of charity goal attainment, message framing, and evidence on persuasion. Journal of Applied Communication Research, 36(2), 161-175. https://doi. org/10.1080/00909880801922854

Davies, B., \& Harré, R. (1990). Positioning: The discursive production of selves. Journal for the Theory of Social Behaviour, 20(1), 43-63. https://doi.org/10.1111/j.1468-5914.1990.tb00174.x

Fahnestock, J. (2011). Rhetorical style: The uses of language in persuasion. Oxford University Press.

Getchell, K. M., \& Beitelspacher, L. S. (2020). Better marketing for female marketers: Gendered language in the Forbes CMO list. Business Horizons, 63(5), 607-617. https://doi. org/10.1016/j.bushor.2020.04.004

Gill, R., \& Wells, C. C. (2014). Welcome to the 'Hunger Games': An exploration of the rhetorical construction of legitimacy for one U.S.-based nonprofit organization. Management Communication Quarterly, 28(1), 26-55. https://doi.org/10.1177/08933|89|35|3434

Harré, R. (2012). Positioning theory: Moral dimensions of social-cultural psychology. In J. Valsiner (Ed.), The Oxford Handbook of Culture and Psychology (pp. 191-206). Oxford University.

Harré, R., \& Gillett, G. (1994). The discursive mind. SAGE.

Harré, R., \& Langenhove, L. V. (1991). Varieties of positioning. Journal for the Theory of Social Behaviour, 21(4), 393-407. https://doi.org/10.1111/j.1468-5914.1991.tb00203.x

Harré, R., \& Van Langenhove, L. (2010). Varieties of positioning, people and societies: Rom harré and designing the social sciences. Routledge.

Hung, I. W., \& Wyer, R. S. (2009). Differences in perspective and the influence of charitable appeals: When imagining oneself as the victim is not beneficial. JMR, Journal of Marketing Research, 46(3), 421-434. https://doi.org/10.1509/jmkr.46.3.421

Íñigo-Mora, I. (2004). On the use of the personal pronoun "we" in communities. Journal of Language and Politics, 3(1), 27-52. https://doi.org/10.1075/jlp.3.1.05ini

Kachersky, L., \& Palermo, N. (2013). How personal pronouns influence brand name preference. Journal of Brand Management, 20(7), 558-570. https://doi.org/10.1057/bm.2012.61

Klass, O. S., Biham, O., Levy, M., Malcai, O., \& Solomon, S. (2006). The Forbes 400 and the Pareto wealth distribution. Economics Letters, 90(2), 290-095. https://doi.org/10.1016/j. econlet.2005.08.020

Masnovi, J. (2013). Persuasive strategies and Hats Off for Cancer donations. Pepperdine Journal of Communication Research 1, 1-11. http://digitalcommons.pepperdine.edu/pjcr/ vol1/iss $1 / 3$

McKeever, B. W. (2013). From awareness to advocacy: Understanding nonprofit communication, participation, and support. Journal of Public Relations Research, 25, 307-328. https:// doi.org/10.1080/1062726X.2013.806868

Merchant, A., Ford, J. B., \& Sargeant, A. (2010). Charitable organizations' storytelling influence on donors' emotions and intentions. Journal of Business Research, 63, 754-762. https://doi.org/10.1016/j.jbusres.2009.05.013

Mitchell, S., \& Clark, M. (2021). Telling a different story: How nonprofit organizations reveal strategic purpose through storytelling. Psychology and Marketing, 38(1), 142-158. https:// doi.org/10.1002/mar.21429 
Moghaddam, F., \& Harré, R. (2010). Words, conflicts and political processes. In F. Moghaddam \& R. Harré (Eds.), Words of war: How the language we use in political processes sparks fighting (pp. 1-28). Praeger.

Moghaddam, F. M., Harré, R., \& Lee, N. (Eds.). (2008). Conclusion and glossary. In Global conflict resolution through positioning analysis. Springer Science + Business Media.

Mühlhäusler, P., \& Harré, R. (1990). Pronouns and people: The linguistic construction of social and personal identity. Blackwell.

National Philanthropic Trust. (2019). Charitable Giving Statistics. National Philanthropic Trust. Retrieved August 8, 2020, from https://www.nptrust.org/philanthropic-resources/ charitable-giving-statistics/\#: : text=General\%20Philanthropy,a\%205.1\%25\%20 increase $\% 20$ from $\% 202018$.\&text=Corporate $\% 20$ giving\%20in $\% 202019 \% 20$ increased,a\%2013.4\%25\%20increase $\% 20$ from\%202018.\&text=Foundation\%20givin

O'Connor, C., \& Joffe, H. (2020). Intercoder reliability in qualitative research: Debates and practical guidelines. International Journal of Qualitative Methods, 19, 1-13. https://doi. org/10.1177/1609406919899220

Paarlberg, L. E., \& Hwang, H. (2017). The heterogeneity of competitive forces: The impact of competition for resources on United Way fundraising. Nonprofit and Voluntary Sector Quarterly, 46(5), 897-921. https://doi.org/10.1177/0899764017713874

Packard, G., Moore, S. G., \& McFerran, B. (2018). (I'm) happy to help (you): The impact of personal pronoun use in customer-firm interactions. JMR, Journal of Marketing Research, 55(4), 541-555.

Pang, N., \& Law, P. W. (2017). Retweeting \#WorldEnvironmentDay: A study of content features and visual rhetoric in an environmental movement. Computers in Human Behavior, 69, 54-61. https://doi.org/10.1016/j.chb.2016.12.003

Pennebaker, J. W. (2011). The secret life of pronouns: What our words say about us. Bloomsbury Press.

Saunders, B., Sim, J., Kingstone, T., Baker, S., Waterfield, J., Bartlam, B., Burroughs, H., \& Jinks, C. (2018). Saturation in qualitative research: Exploring its conceptualization and operationalization. Quality \& Quantity, 52, 1893-1907. https://doi.org/10.1007/s11135017-0574-8

Sela, A., Wheeler, S. C., \& Sarial-Abi, G. (2012). WeAre not the same asYou and I: Causal effects of minor language variations on consumers' attitudes toward brands. Journal of Consumer Research, 39(3), 644-661. https://doi.org/10.1086/664972

Shier, M. L., \& Handy, F. (2012). Understanding online donor behavior: The role of donor characteristics, perceptions of the internet, website and program, and influence from social networks. International Journal of Nonprofit and Voluntary Sector Marketing, 17(3), 219230. https://doi.org/10.1002/nvsm.1425

Smitko, K. (2012). Donor engagement through twitter. Public Relations Review, 38, 633-635. https://doi.org/10.1016/j.pubrev.2012.05.012

Urban Institute. (2020). National Center for Charitable Statistics, Retrieved August 8, 2020, from Urban Institute: https://nccs.urban.org/.

Van Langenhove, L., \& Harre, R. (1999). Positioning theory. Blackwell Publishing.

\section{Author Biographies}

Paula Lentz is a professor of business communication and academic program director in the Department of Business Communication at the University of Wisconsin-Eau Claire. Her 
scholarship interests include rhetorical theory and business communication, disciplinary identity in business communication, and discourse analysis.

Kristen Getchell is an associate professor in the Marketing Division at Babson College. Her research employs rhetorical theory, genre history, the scholarship of teaching and learning, and historical methodologies to study business communication.

James Dubinsky is the executive director of the Association for Business Communication, an associate professor of English at Virginia Tech, and the founding director of the university's professional writing program. He is an advocate for military veterans and serves as the lead faculty member in the Veterans in Society initiative at Virginia Tech.

Mary Katherine Kerr is an MBA student in the UW Consortium MBA Program. In addition to completing her MBA degree, she works as an operations-human resources administrator. 